\title{
Da Vinci robot-assisted resection to treat abdominal ectopic thyroid: a case report and literature review
}

\author{
Zhanwei Zhao $^{1 \wedge}$, Yun Huang ${ }^{1}$, Xiliang Zhang ${ }^{1}$, Huibin Zhao ${ }^{1}$, Xinpu Yuan ${ }^{1}$, Qiwen Zhao ${ }^{2}$, \\ Chaojun Zhang ${ }^{1}$ \\ ${ }^{1}$ Department of General Surgery, The Sixth Medical Center of PLA General Hospital, Beijing, China; ${ }^{2}$ Department of Pathology, The Sixth Medical \\ Center of PLA General Hospital, Beijing, China \\ Correspondence to: Prof. Chaojun Zhang. Department of General Surgery, The Sixth Medical Center of PLA General Hospital, Beijing 100048, \\ China. Email: 1939618043@qq.com.
}

\begin{abstract}
Although ectopic thyroid can be found in thoracic locations, the discovery of abdominal ectopic thyroid is often an accidental event. Moreover, abdominal ectopic thyroid is easily misdiagnosed due to the rarity of these cases and the difficulties in the preoperative diagnosis process. Thus, we aimed to assess the prevalence and features of abdominal ectopic thyroid and to highlight the current knowledge about the clinical characteristics and management of this condition by analyzing a case report of abdominal ectopic thyroid and reviewing the literature. A 70-year-old woman with a 3-year history of gradually increasing abdominal distension in the right lower quadrant of the abdomen was admitted to the hospital. Contrastenhanced computed tomography (CT) of the abdomen revealed a retroperitoneal mass. The patient underwent Da Vinci robotic surgery, and the retroperitoneal mass was completely resected. Subsequently, the pathologic diagnosis of the mass was ET. The patient had no discomfort or symptoms when she was discharged from the hospital and at the postoperative 1, 3, 6, 9 and 12 months follow-up. The summary of literature review suggested that abdominal ectopic thyroid is still rare although there are some reports. Nonetheless, the cause of abdominal ectopic thyroid is unclear, and abdominal ectopic thyroid has the following characteristics: more common in women than in men, asymptomatic in the majority of the cases, difficult to diagnose, and found by excluding metastasis. Most ectopic thyroid is treated with surgery, and minimally invasive techniques have been increasingly performed. This is the first report on Da Vinci robotic resection for large rare retroperitoneal ET, and this case highlights that ET should be considered when patients present with similar imaging findings in the abdomen.
\end{abstract}

Keywords: Case report; ectopic thyroid; abdomen; Da Vinci robot

Submitted Jun 17, 2020. Accepted for publication Nov 12, 2020.

doi: $10.21037 / \mathrm{gs}-20-565$

View this article at: http://dx.doi.org/10.21037/gs-20-565

\section{Introduction}

In 1953, Horst et al. reported the first case of hypothyroidism in which an ectopic thyroid (ET) was diagnosed by the absence of symptoms based on an ${ }^{131} \mathrm{I}$ scan (1). ET is an infrequently observed condition and is more frequent in females than in males. During the fourth embryonic week, the thyroid tissue starts developing. The thyroid tissue is normally located anterior to the trachea by the seventh embryonic week. Although the cause of ET is still not fully known, the disrupted thyroid migration during the embryonic period may explain this disease (2). Clinically, an occasional mass or unexplained obstruction related to ET location and size could be observed. Abdominal tumors arise from various reasons, and the diagnosis of abdominal tumors is very difficult. Most patients with abdominal ET

$\wedge$ ORCID: 0000-0002-0485-8229. 

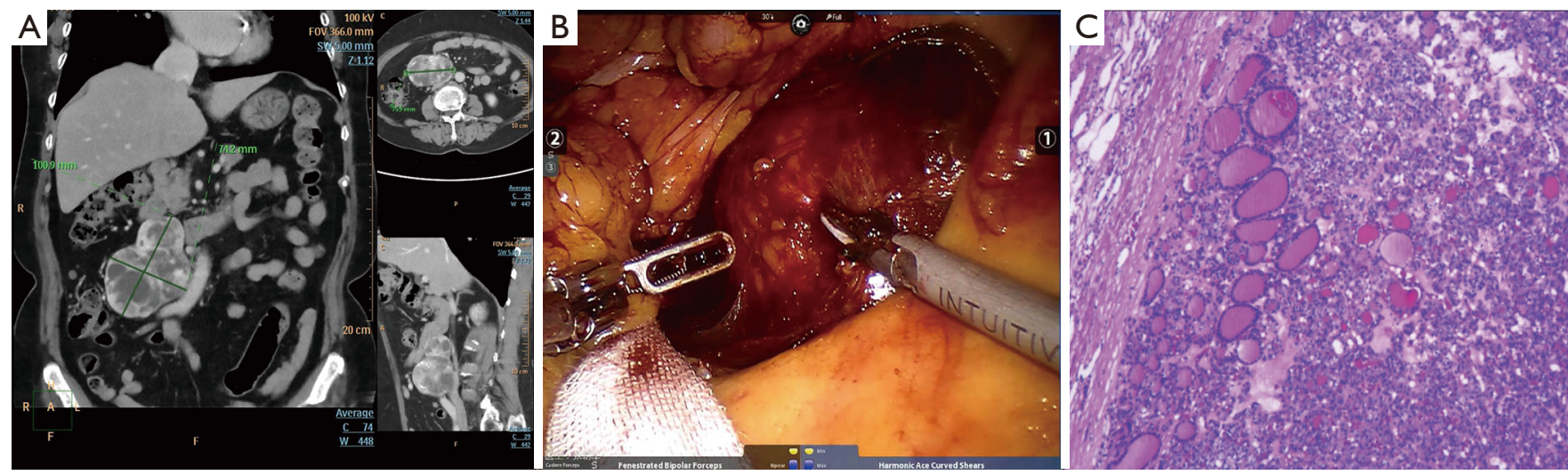

Figure 1 Contrast-enhanced computed tomography of the abdomen revealed a retroperitoneal mass with a size of $100.9 \mathrm{~mm} \times 74.2 \mathrm{~mm} \times$ $75.9 \mathrm{~mm}$ (A). The patient underwent Da Vinci robotic surgery and the retroperitoneal mass was completely resected (B). The pathologic diagnosis of the mass (C, HE staining, magnification 100x).

are asymptomatic, and ruling out metastases from thyroid cancer is important.

Here, we provided a rare case report, which may be helpful for the diagnosis and treatment of abdominal tumors. Furthermore, we also summarized the prevalence, features, diagnosis and surgical management of abdominal ET. We present the following article in accordance with the CARE reporting checklist (available at http://dx.doi. org/10.21037/gs-20-565).

\section{Case presentation}

All procedures performed in studies involving human participants were in accordance with the ethical standards of the institutional and national research committee(s) and with the Helsinki Declaration (as revised in 2013). Written informed consent was obtained from the patient. A 70-yearold woman with a 3-year history of gradually increasing abdominal distension in the right lower quadrant of the abdomen was admitted to the hospital on July 2018. Her family history was negative for thyroid diseases, and the patient had no unusual discomfort. The laboratory results were unremarkable, and no results were positive for cancer markers. Contrast-enhanced computed tomography (CT) of the abdomen revealed a retroperitoneal mass with a size of $100.9 \mathrm{~mm} \times 74.2 \mathrm{~mm} \times 75.9 \mathrm{~mm}$ (Figure 1A). After completing the preoperative examinations, the patient underwent Da Vinci robotic surgery, and the retroperitoneal mass was completely resected (Figure 1B).

Subsequently, the struma ovarii needed to be excluded (Figure 1C). Thus, B-mode ultrasonography and contrast- enhanced CT of the patient's thyroid and bilateral ovaries were performed. Ultimately, the diagnosis of struma ovarii was excluded based on the lack of abnormal examination results.

The pathologic diagnosis of the mass was ET. The follow-up approach was specifically designed for this patient. The patient had no discomfort or symptoms when she was discharged from the hospital and at the postoperative 1, 3, 6, 9 and 12 months follow-up, which were conducted by telephone and at outpatient clinics.

\section{Discussion}

\section{Prevalence and features of abdominal ET}

The specific prevalence of ET is approximately 1 per 100,000-300,000 persons (3). Abdominal tumors arise because of various reasons, and the diagnosis of abdominal tumors is very difficult. ET is most commonly found in the neck, and abdominal ET is relatively rare. We reviewed the English literature in PubMed and summarized the prevalence and features of abdominal ET (Table 1).

Table 1 suggested that ET is common among middleaged and old woman. The major diagnostic methods included hormonal examination, ultrasonography, CT, magnetic resonance imaging (MRI) and fine needle aspiration cytology (FNAC). Some patients have abdominal pain but some patients were asymptomatic and ET was detected incidentally by ultrasonography and CT. Thus, ET should not be hasty excluded when patients present with asymptomatic abdominal mass. It is important, 


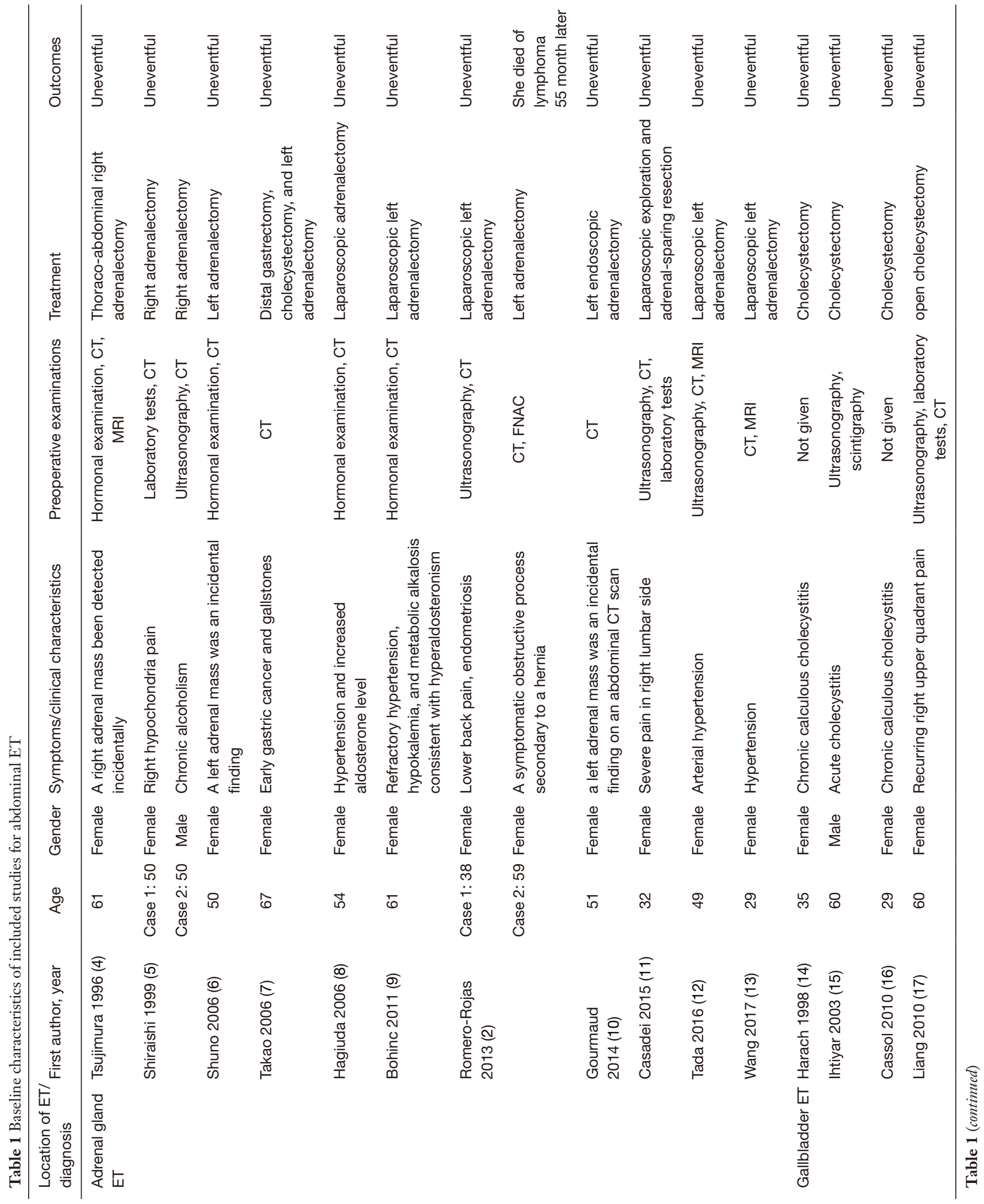




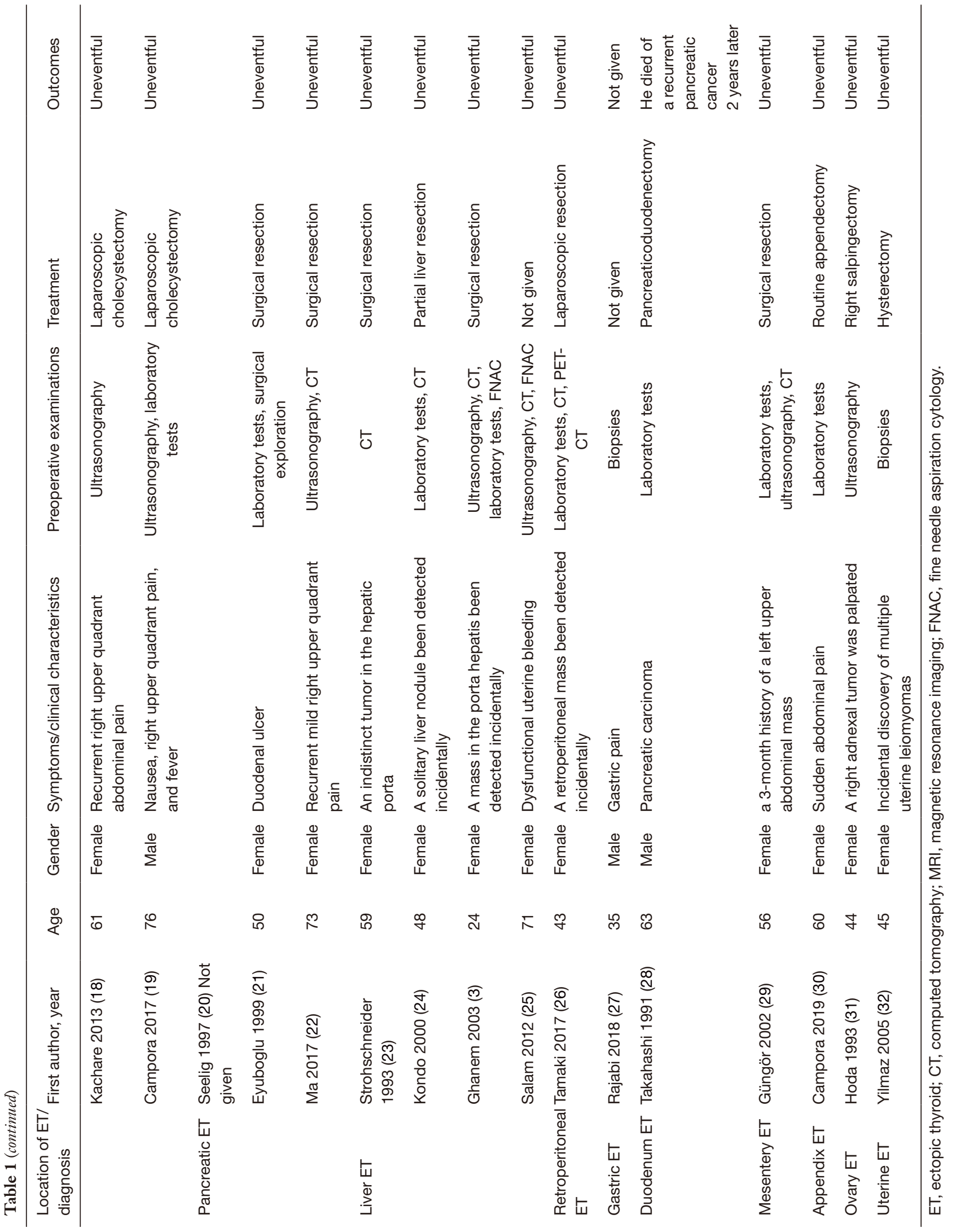


the metastasis of thyroid carcinoma should be ruled out carefully before a diagnosis of ET. Surgical resection was the major treatments. The time of publication showed that the previous surgery methods were mainly open and recently laparoscopy has been reported increasingly with the advancement of minimally invasive techniques.

\section{Adrenal gland ET}

Guerra et al. (33) reported that adrenal gland thyroid is very rare and is difficult to understand based on thyroid embryology. However, on the basis of the reported cases (4-13), the adrenal gland is not an uncommon site of abdominal ET. The cause of adrenal gland ET remains unknown. Although some diseases including adenocarcinoma are associated with adrenal masses with cystic lesions, dermoid cysts and cortical adenoma have been reported, ET should be considered when the adrenal gland shows both normal hormonal data and a cystic lesion.

\section{Gallbladder ET}

ET is occasionally found in the gallbladder. Campora et al. (19) reported that only 3 cases of gallbladder ET have been described. However, to the best of our knowledge, at least 6 case reports on this disease existed in the literature (14-18,34). Gallbladder ET generally has no specialized symptoms but is occasionally associated with recurrent right abdominal pain. ET could be observed in the wall of the gallbladder.

\section{Pancreatic ET}

Although ET could be found along the descending glands, ET in the pancreas is rare. To the best of our knowledge, 3 studies have been reported on pancreatic ET (20-22). All the patients were middle-aged women, and all lesions had sizes of approximately $70 \mathrm{~mm} \times 30 \mathrm{~mm}$. One of the three patients had no symptoms with a diagnosis of pancreatic cancer (20), one had recurrent pain in the right upper quadrant with a diagnosis of neuroendocrine neoplasm (22), and one had a complaint about dyspeptic symptoms with a diagnosis of a duodenal ulcer (21).

\section{Liver ET}

ET in the liver rarely occurs. Only three cases of ET in the liver $(24,25)$ and porta hepatis (3) have been reported. Additionally, a German report was also found in the references when we conducted out literature search (23). All patients were women. Since the liver is an organ easily metastasized by cancers, ruling out thyroid cancer metastasis before the diagnosis of ET is important. Moreover, whether ET is combined in the liver metastases is key. Kondo et al. (24) reported a mimicking ET in a 48-year-old woman with follicular carcinoma of the thyroid. However, the author also discussed that the liver tumor may not be an ET but rather an incidentally detected liver metastasis.

\section{Gastric ET}

ET is considered as normal thyroid tissue in the gastric mucosa and along the gastrointestinal tract (33). However, distinguishing between metastatic thyroid cancer and normal thyroid tissue inside the stomach is important. ET was discovered in the stomach of a 35-year-old man without a thyroid tumor who suffered from gastric pain for six months. Biopsies were taken, and the microscopy sections showed thyroid tissue composed of colloid material and follicular cells (27).

\section{Other sites}

The other sites of abdominal ET included the duodenum (28), mesentery (29), appendix (30), gynecological organs [ovary (31) and uterus (32)] and retroperitoneal ET (26). Although few cases of other sites of abdominal ET have been reported, struma ovarii is a noteworthy disease because this condition may be easily misdiagnosed, and determining benign disease from malignant disease is difficult. Struma ovarii is diagnosed on the basis of thyroid tissue in the ovarian structures. Most patients with struma ovarii are asymptomatic, and the condition is incidentally found on ultrasonography or CT. The pathological diagnosis of our patient also suggested that struma ovarii should be excluded, based on further examinations and the combination of those results with clinical symptoms; the patient was ultimately diagnosed with ET.

\section{Diagnosis}

The mechanism of how ET migrates into the abdomen is not fully understood. Cassol et al. (16) reported that ET in the gastrointestinal tract, liver and pancreas could be explained as a heteroplastic or metaplastic phenomenon because these locations and the thyroid share a common embryologic origin from the foregut endoderm. The thyroid gland tissue is composed of two cell types, the C cells and the thyroid follicular cells (27). Romero-Rojas et al. (2) showed that the lack of $\mathrm{C}$ cells in histology and immunohistochemical profiles is one of the important diagnostic criteria. 
Iodine-131 or technetium-99m pertechnetate have been employed to discover ET and is based on the typical characteristics of thyroid tissues uptaking radioisotopes. Most patients were admitted to the hospital after the abdominal mass was accidentally found. Nonetheless, radioactive examinations are rarely performed for patients without symptoms. CT scans, B-mode ultrasonography and MRI are the main imaging tools for abdominal ET. Our case and Table 1 indicated that CT is very useful for detecting the location, size and configuration of ET, which is instructive for surgical resection especially for minimally invasive surgery. FNAC provides correct diagnoses at a rate higher than $95 \%$ and is considered the most accurate diagnostic method. FNAC is a very useful diagnostic tool when ET is not identified, especially before a surgery. Occasionally, intraoperative frozen pathology is also an effective method for some suitable patients.

\section{Management}

The best treatment strategy for ET is linked to the patient conditions, including age, sex, location of ET, local symptoms, tumor malignancy, anesthesiological risk assessment score and thyroid functional status. Most abdominal ET is treated with surgical resection. Rare cases are treated with palliative therapy after a diagnosis with puncture pathology. The surgical methods include open surgery, laparoscopy and Da Vinci robotics. Limited by technology, the previous surgery methods were mainly open. With the advancement of minimally invasive techniques, laparoscopy has been reported for abdominal ET (26). No current studies of Da Vinci robotic resection for ET exist because of the complexity of the surgery and rarity of this condition. There was no contraindication for robotic surgery after preoperative evaluation and we performed robotic surgery to treat abdominal ET. Our case suggested that robotic surgery is safe and effective for treating suitable abdominal ET, which may be helpful for abdominal tumor therapy.

Our report has several strengths. The first strength was that we systematically reviewed the literature, which provided robust and reliable data for rare abdominal ET. Second, we firstly reported the Da Vinci robotic resection for large retroperitoneal ET, which is helpful for selecting minimally invasive techniques to the similar mass. Third, we summarized the clinical characteristics of abdominal ET including age, gender, location, symptoms, diagnosis, treatment and outcomes, which increased the generalizability of our conclusions. However, the limitations of our report should be taken into consideration. First, the various locations of ET could be observed especially in the neck but our report only focused on the abdominal ET. Thus, our results and conclusions should be considered carefully due to the limitations. Second, although we tried to analyze the possible etiology and development of ET, we still not determined the pathogenesis and the future studies are needed. Third, the hormonal examinations and clinical characteristics of some patients were not remarkable. We will continue focus on the similar reports and track our patients to develop better guidance for this disease.

\section{Conclusions}

Abdominal ET is still rare, although there are some reports, as seen above. Nonetheless, the cause of abdominal ET is unclear, and abdominal ET has the following characteristics: more common in women than in men, asymptomatic in the majority of the cases, difficult to diagnose, and found by excluding metastasis. Most ET is treated with surgery, and minimally invasive techniques have been increasingly performed. To our knowledge, this is the first report on Da Vinci robotic resection for large rare retroperitoneal ET, and this case highlights that ET should be considered when patients present with similar imaging findings in the abdomen.

\section{Acknowledgments}

Funding: This work was supported by funding from National Natural Science Foundation of China (NSFC81972320), the Innovation Funds of Navy General Hospital (CXPY201801) and the Funds of Bethune Charitable Foundation (HZB-20181119-71).

\section{Footnote}

Reporting Checklist: The authors have completed the CARE reporting checklist. Available at http://dx.doi.org/10.21037/ gs-20-565

Conflicts of Interest: All authors have completed the ICMJE uniform disclosure form (available at http://dx.doi. org/10.21037/gs-20-565). The authors have no conflicts of interest to declare.

Etbical Statement: The authors are accountable for all 
aspects of the work in ensuring that questions related to the accuracy or integrity of any part of the work are appropriately investigated and resolved. All procedures performed in this study involving human participants were in accordance with the ethical standards of the institutional committee, and with the Helsinki Declaration (as revised in 2013). Written informed consent was obtained from the patient for publication for this case report and any accompanying images.

Open Access Statement: This is an Open Access article distributed in accordance with the Creative Commons Attribution-NonCommercial-NoDerivs 4.0 International License (CC BY-NC-ND 4.0), which permits the noncommercial replication and distribution of the article with the strict proviso that no changes or edits are made and the original work is properly cited (including links to both the formal publication through the relevant DOI and the license). See: https://creativecommons.org/licenses/by-nc-nd/4.0/.

\section{References}

1. Kaplan M, Kauli R, Lubin E, et al. Ectopic thyroid gland. A clinical study of 30 children and review. J Pediatr 1978;92:205-9.

2. Romero-Rojas A, Bella-Cueto MR, Meza-Cabrera IA, et al. Ectopic thyroid tissue in the adrenal gland: a report of two cases with pathogenetic implications. Thyroid 2013;23:1644-50.

3. Ghanem N, Bley T, Altehoefer C, et al. Ectopic thyroid gland in the porta hepatis and lingua. Thyroid 2003;13:503-7.

4. Tsujimura A, Takaha M, Takayama H, et al. Ectopic thyroid tissue in a cystic adrenal mass. Br J Urol 1996;77:605-6.

5. Shiraishi T, Imai H, Fukutome K, et al. Ectopic thyroid in the adrenal gland. Hum Pathol 1999;30:105-8.

6. Shuno Y, Kobayashi T, Morita K, et al. Ectopic thyroid in the adrenal gland presenting as cystic lesion. Surgery 2006;139:580-2

7. Takao H, Doi I, Watanabe T. Ectopic thyroid in the adrenal gland: Computed tomography findings. J Comput Assist Tomogr 2006;30:221-2.

8. Hagiuda J, Kuroda I, Tsukamoto T, et al. Ectopic thyroid in an adrenal mass: a case report. BMC Urol 2006;6:18.

9. Bohinc BN, Parker JC, Hope WW, et al. Micropapillary thyroid carcinoma and concomitant ectopic thyroid tissue in the adrenal gland: metastasis or metaplasia? Thyroid
2011;21:1033-8.

10. Gourmaud J, Bongiovanni M, Triponez F, et al. Ectopic thyroid tissue in the adrenal gland. Endocr Pathol 2014:25:353-5.

11. Casadei GP, Bertarelli C, Giorgini E, et al. Ectopic thyroid tissue in the adrenal gland: report of a case. Int J Surg Pathol 2015;23:170-5.

12. Tada A, Tanaka T, Takamoto A, et al. Ectopic thyroid tissue in the adrenal gland: CT and MRI findings. Diagn Interv Imaging 2016;97:373-5.

13. Wang SC, Hung SW, Lee CH, et al. Ectopic Thyroid Tissue in the Adrenal Gland Mimicking a Pheochromocytoma. J Endourol Case Rep 2017;3:149-151.

14. Harach HR. Ectopic thyroid tissue adjacent to the gallbladder. Histopathology 1998;32:90-1.

15. Ihtiyar E, Isiksoy S, Algin C, et al. Ectopic thyroid in the gallbladder: report of a case. Surg Today 2003;33:777-80.

16. Cassol CA, Noria D, Asa SL. Ectopic thyroid tissue within the gall bladder: case report and brief review of the literature. Endocr Pathol 2010;21:263-5.

17. Liang K, Liu JF, Wang YH, et al. Ectopic thyroid presenting as a gallbladder mass. Ann R Coll Surg Engl 2010;92:W4-6.

18. Kachare MB, Khandelwal A, Kulkarni SB, et al. Ectopic thyroid in duplicated gall bladder: a rare entity. Case report. Med Ultrason 2013;15:73-5.

19. Campora M, Trambaiolo AC, Mastracci L, et al. A Never Ending Journey: Ectopic Thyroid. Int J Surg Pathol 2017;25:241-2.

20. Seelig MH, Schonleben K. Intra-abdominal ectopic thyroid presenting as a pancreatic tumour. Eur J Surg 1997;163:549-51.

21. Eyuboglu E, Kapan M, Ipek T, et al. Ectopic thyroid in the abdomen: report of a case. Surg Today 1999;29:472-4.

22. Ma A, Liu H. Ectopic thyroid of the pancreas: A case report and literature review. Medicine (Baltimore) 2017;96:e8707.

23. Strohschneider T, Timm D, Worbes C. Ectopic thyroid gland tissue in the liver. Chirurg 1993;64:751-3.

24. Kondo T, Katoh R, Omata K, et al. Incidentally detected liver metastasis of well-differentiated follicular carcinoma of the thyroid, mimicking ectopic thyroid. Pathol Int 2000;50:509-13.

25. Salam M, Mohideen A, Stravitz RT. Ectopic thyroid presenting as a liver mass. Clin Gastroenterol Hepatol 2012;10:xxx.

26. Tamaki S, Miyakura Y, Someya S, et al. Laparoscopic 
resection of retroperitoneal ectopic thyroid tissue. Asian J Endosc Surg 2017;10:331-3.

27. Rajabi P, Eftekhari SM, Rouhani E, et al. Ectopic Thyroid in Stomach; a Case Report. Iran J Pathol 2018;13:103-5.

28. Takahashi T, Ishikura H, Kato H, et al. Ectopic thyroid follicles in the submucosa of the duodenum. Virchows Arch A Pathol Anat Histopathol 1991;418:547-50.

29. Güngör B, Kebat T, Ozaslan C, et al. Intra-abdominal ectopic thyroid presenting with hyperthyroidism: report of a case. Surg Today 2002;32:148-50.

30. Campora M, Trambaiolo AC, Valle L, et al. Abdominal

Cite this article as: Zhao Z, Huang $\mathrm{Y}$, Zhang $\mathrm{X}$, Zhao H, Yuan X, Zhao Q, Zhang C. Da Vinci robot-assisted resection to treat abdominal ectopic thyroid: a case report and literature review. Gland Surg 2021;10(1):378-385. doi: 10.21037/gs-20-565
Ectopic Thyroid Tissue: The Man From Istanbul. Int J Surg Pathol 2019;27:553-5.

31. Hoda SA, Huvos AG. Struma salpingis associated with struma ovarii. Am J Surg Pathol 1993;17:1187-9.

32. Yilmaz F, Uzunlar AK, Sogutcu N. Ectopic thyroid tissue in the uterus. Acta Obstet Gynecol Scand 2005;84:201-2.

33. Guerra G, Cinelli M, Mesolella M, et al. Morphological, diagnostic and surgical features of ectopic thyroid gland: a review of literature. Int J Surg 2014;12 Suppl 1:S3-11.

34. Curtis LE, Sheahan DG. Heterotopic tissues in the gallbladder. Arch Pathol 1969;88:677-83. 